\title{
POLÍTICA PÚBLICA EMERGENCIAL E O NOVO MECANISMO TRANSDISCIPLINAR
}

\author{
Arianne Brito Cal Athias* \\ Jéssica Rabelo Barbosa**
}

\begin{abstract}
RESUMO: O presente artigo trata do Programa Emergencial de Manutenção de Emprego e Renda, como um instrumento de política pública do governo federal com objetivo de mitigar os impactos trabalhista e econômicos decorrente do Covid-19. A ênfase é refletir Direito do Trabalho como um direito fundamental social e digno diante dos desafios sociais e econômicos, entender o programa e a aplicação da Lei $\mathrm{n}^{\circ}$ 14.020/20. Contudo o artigo também inicia uma reflexão e apresenta o Nudge como um mecanismo alternativo e eficiente de políticas públicas com intuito de fortalecer cidadão, governo e as instituições privadas sem violar os direitos fundamentais sociais.
\end{abstract}

PALAVRAS-CHAVE: Política Pública; Dignidade; Transdisciplinariedade; Nudge; Direito Fundamental.

\section{EMERGY PUBLIC POLICY AND THE NEW TRANSDISCIPLINARY MECHANISM}

ABSTRACT: This article deals with the Emergency Employment and Income Maintenance Program, as a public policy instrument of the federal government with the objective of mitigating the labor and economic impacts resulting from Covid-19. The emphasis is to reflect Labor Law as fundamental social and dignified right in the face of social and economic challenges, to understand the program and the application of Law No. 14,020 / 20. However, the article also initiates a reflection and presents Nudge as an alternative and efficient public policy mechanism with the aim of strengthening citizens, government and private institutions without violating fundamental social rights.

KEYS WORDS: Public Policies; Dignity; Transdisciplinary; Nudge; Fundamental Right.

\section{INTRODUÇÃO}

As políticas públicas na esfera trabalhista são um grande desafio, pois sua sistemática envolve tanto a esfera pública quanto a esfera privada. Durante a pandemia do COVID-19,

\footnotetext{
* Doutora em Direito Administrativo pela PUC de São Paulo (2007). Mestra em Direito pela Universidade da Amazônia (2001). Professora Adjunta III da Universidade Federal do Pará - UFPA, cedida ao Ministério Público do Estado do Pará para exercer o cargo em comissão de Assessor do Procurador-Geral de Justiça. Professora Titular I de Graduação e do Programa de Pós Graduação em Direitos Fundamentais (Mestrado) da Universidade da Amazônia - UNAMA. Admitida para o curso Pós-doutoramento em Direito. As Gerações dos Direitos Humanos no Marco dos Direitos Sociais. Perspectiva Comparada: Brasil e Espanha - 2021 na Universidade de Salamanca USAL/Espanha. E-mail: arianneathias@gmail.com.

** Especialista em Processo Civil e Processo do Trabalho (2018). Especialista em Direito Digital e Compliance pela Damásio (2019). Mestranda pela Universidade da Amazônia - UNAMA. Advogada em Belém. E-mail: advjessicabarbosa@yahoo.com
} 
vê-se um governo empenhado em garantir o mínimo existencial à população sem, contudo, que esse o faça de forma eficiente.

Nesse primeiro momento, é importante visualizar a definição de políticas públicas segundo o professor Bruno Campos Cunha (2011, p.71) "como sendo o conjunto de programas e estratégias, desempenhadas pelo Estado com a finalidade principal de efetivação dos direitos fundamentais e sociais."

Embora a definição de políticas públicas seja um campo de grandes debates e reflexões não é o objetivo deste artigo analisar definições doutrinárias. A definição supramencionada é concisa e sacia a necessidade deste trabalho.

Torna-se imprescindível reconhecer a integração interdisciplinar com o direito fundamental social, a dignidade da pessoa humana e o mínimo existencial. O quanto essa interrelação é necessária para haver o mínimo de respeito ao direito do trabalhador mesmo em tempo de calamidade social.

Ademais, o presente artigo inicia a exposição da Política Público do Governo Federal diante dos desafios sociais e econômicos ocasionados pela pandemia do Covid-19: o Programa Emergencial de Manutenção de Emprego e Renda. Detalhando os objetivos, o teor principal e de que maneira o governo está administrando tal política e sua influência no setor social e econômico.

O Programa Emergencial de Manutenção de Emprego e Renda foi instituído pelo governo federal, através do Ministério da Economia, por meio da Medida Provisória $\mathrm{n}^{\circ}$ 936, que posteriormente o Presidente da República sancionou a Lei no $14.020 / 2020$. Este programa oferece medidas trabalhistas para o enfrentamento do estado de calamidade pública e da emergência de saúde pública decorrente do coronavirus (Covid-19). O benefício será pago quando houver acordo entre trabalhadores e empregadores nas situações de: redução proporcional de jornada de trabalho e salário, bem como suspensão temporária do contrato de trabalho. Segundo o portal do governo da economia ${ }^{1}$ já foram preservados mais de 18 milhões de postos de trabalho.

\footnotetext{
${ }^{1}$ Ministério da Economia. Disponível em: https://servicos.mte.gov.br/bem/. Acesso: 20 de setembro de 2020.
} 
Foi explorado também os dados referentes do que a Lei $\mathrm{n}^{\circ}$ 14.020/20 está propondo, ou seja, indicadores mostram como as empresas irão se comportar frente a essa política, bem como que redução de fato os trabalhadores terão e o que irá diminuir. A importância desse tópico se dá uma vez que, as informações não estão sendo prestadas de forma completa, pois a maioria das pessoas só tem o conhecimento da redução e da suspensão, sem, contudo, saber de fato como se dará essas medidas. Portanto, viu-se a necessidade de uma exposição clara, fácil e objetiva.

Embora seja uma medida emergencial, foi observado que, pela deficiência na apresentação do plano, como por exemplo falta de demonstração na aplicação e possíveis ganhos ou perdas de quem concordava em utilizá-lo, iniciou uma reflexão sobre o mecanismo chamado Nudges.

A intenção deste artigo é iniciar uma reflexão acerca desse instrumento, porém em uma visão ampla, é possível observar, nesse cenário, uma oportunidade para o agora e o futuro. Que se baseia em uma economia comportamental para melhorar as tomadas de decisões no setor público.

A economia comportamental, ao contrário do pensamento econômico clássico fundado na racionalidade plena, passou a considerar aspectos psicológicos, cognitivos e sociais do comportamento que podem influenciar nas escolhas das pessoas. Assim sendo, realizar intervenções comportamentais fundamentadas em evidências, num contexto de recursos escassos e demandas sociais ilimitadas, são desejáveis, pois podem contribuir para um melhor processo de formulação e implantação de políticas públicas.

Com isso, desenvolve-se a definição do Nudge no campo da arquitetura da decisão. Essa arquitetura possibilita escolhas que podem melhorar a vida das pessoas por intermédio de informações auxiliares que conduzam as pessoas a fazerem escolhas com efeitos mais positivos, tanto individual como coletivamente.

Nudges não são uma proposta de normas complexas, mas foram idealizadas para direcionar um comportamento que é voltado para um interesse da sociedade como um todo. $\mathrm{O}$ assunto ainda causa vários debates, mas é importante ressaltar que no setor público esse instrumento pode ser utilizado para o desenvolvimento de políticas públicas mais efetivas, e geralmente com custo baixo. 
Desta forma, objetivo do artigo é discutir a utilização da economia comportamental como forma de auxiliar na organização, implementação e comunicação de Políticas Públicas. Através da aplicação desse novo mecanismo é possível desenvolver Políticas Públicas de forma a garantir trabalho digno e assim proteger a Dignidade da Pessoa Humana.

$\mathrm{O}$ artigo apresenta uma abordagem qualitativa, aplicada e exploratória utilizando o procedimento de revisão bibliográfica; abordando direito constitucional ao trabalho, economia comportamental e nudge que devem ser considerados para realizar o planejamento das ações e programas de políticas públicas com foco no direito do trabalho.

\section{DIREITO FUNDAMENTAL SOCIAL E O MINIMO EXISTENCIAL}

A sociedade e as constantes evoluções têm exigido do Estado mais do que um mero espectador e protetor de direito fundamentais individuais e sociais. Atualmente o Estado tem o encargo, de forma genérica, de satisfazer direitos sociais com ações positivas e nessa atividade busca-se a valorização da dignidade humano perfazendo juntamente com o mínimo existencial. Embora muitos sejam os desafios legislativos e doutrinário, é necessário o entendimento, ainda que superficial, da relação estrita dos direitos fundamentais sociais, a dignidade da pessoa humana e o mínimo existencial.

A priori, é relevante sublinhar o que Leivas (2006) entende sobre ações positivas, qual seja, é uma mudança casual de situações ou processo na realidade. Nesse contexto, é fácil deslumbrar como a realidade social vem determinando ações positivas pelo Estado, por exemplo, o tempo do covid-19, onde requereu do Estado proteção aos direitos fundamentais individuais e sociais, como saúde, trabalho e educação.

Nesse contexto é interessante trazer ao conhecimento o modelo triádico duplo. Segundo a ideia de Alexy no tempo de crise os direitos fundamentais merecem uma proteção jusfundamental, por mais que seja mínima.

Partindo dessa ideia, é visível as ações do governo brasileiro se comportando como um estado jusfundamental, uma vez que tem buscado urgentemente a proteção dos direitos fundamentais sociais e individuais. 
Esse modelo só é utilizado pelo Estado em situações extremas, pois assim ele poderá adotar medidas que garantam o pleno exercício dos direitos fundamentais, sejam eles individuais ou sociais.

A partir do entendimento da atividade estatal com o modelo supracitado em conjunto com suas ações positivas, Coelho (2017, p.91), em breves palavras, define que "os direitos sociais são, portanto, direitos fundamentais a prestações em sentido stricto”.

Não obstante, para Jose Afonso da Silva, os direitos sociais, são:

como uma dimensão dos direitos fundamentais do homem, são prestações positivas proporcionadas pelo Estado diretamente ou indiretamente, enunciadas em normas constitucionais, que possibilitam melhores condições de vida aos mais fracos, direitos que tendem a realizar a igualização de situações sociais desiguais. São, portanto, direitos que se ligam ao direito de igualdade $(\ldots)^{2}$

É válido ainda ressaltar Vidal Serano Nunes que sintetiza as questões dos direitos sociais na seguinte afirmação:

[...] podemos conceituar direitos sociais como o subsistema dos direitos fundamentais que, reconhecendo a existência de um segmento social economicamente vulnerável, busca, quer por meio da atribuição de direitos prestacionais, que pela normatização e regulação das relações econômicas, ou ainda pela criação de instrumentos assecuratórios de tais direitos, atribuir a todos os benefícios da vida em sociedade. ${ }^{3}$

É importante frisar também que a Constituição Federal de 1988 abrange de modo detalhado o rol dos direitos fundamentais sociais, bem como as tarefas aos poderes públicos em diversos campos, como saúde, trabalho, educação entre outros.

Há muitos conceitos doutrinários, no entanto, o que é importante estabelecer é que os direitos sociais estão intrinsecamente ligados aos direitos individuais e, consequentemente, a dignidade da pessoa humana. Isto é, a inefetividade do Estado nas atividades prestacionais ou ainda na atividade normativa e reguladora poderá violar a dignidade do indivíduo, bem como prejudicar a prestação do mínimo para o bem estar social.

\footnotetext{
${ }^{2}$ COELHO apud, p. 92

${ }^{3}$ COELHO apud, p. 93
} 
Nesse contexto é necessário ainda reconhecer a estrita relação entre mínimo existencial e a dignidade humana juntamente com os direitos fundamentais sociais.

Foi o alemão Atto Bachof, que afirmou pela primeira vez que o princípio da dignidade da pessoa humana não requer apenas a liberdade, mas também o mínimo de segurança social, isto é, o mínimo existencial.

Na visão da Corinna Treish o mínimo existencial é:

A parte do consumo corrente de cada ser humano, seja criança ou adulto, que é necessário para a conservação de uma vida humana digna, o que compreende a necessidade de vida física, como a alimentação, vestuário, moradia, assistência de saúde, etc. (o mínimo existencial físico) e a necessidade espiritual-cultural, como educação, sociabilidade, etc. Compreende a definição do mínimo existencial tanto a necessidade física como também cultural-espiritual, então se fala de um mínimo existencial cultural. ${ }^{4}$

O mínimo existencial, segundo Barcellos, pode ser definido como "um elemento constitucional essencial, pelo qual se deve garantir um conjunto de necessidades básicas do indivíduo". 5

É também relevante destacar o entendimento do Supremo Tribunal Federal quanto a questão do mínimo existencial, vejamos:

Compreende um complexo de prerrogativa cuja concretização revela-se capaz de garantir condições adequadas de existência digna, em ordem a assegurar, à pessoa, acesso efetivo ao direitos geral de liberdade e, também, a prestações positivas originárias do Estado, viabilizadoras da plena fruição de direitos sociais básicos, tais como o direito à educação, o direito à proteção integral da criança e do adolescente, o direito à saúde, o direito à assistência social, o direito à moradia, o direito à alimentação, direito ao trabalho...

Além disso é imperioso sublinhar um trecho da famosa ADPF 45, do Ministro Celso de Mello onde tece considerações acerca do mínimo existencial.

\footnotetext{
${ }^{4}$ LEIVAS apud Corinna Treisch. Teoria dos Direitos Fundamentais Sociais. p. 135

${ }^{5}$ BARCELLOS, A. P. de. A eficácia jurídica dos princípios constitucionais. O princípio da dignidade da pessoa humana. Rio de Janeiro: Renovar, 2002. In: MORAES, D.P.H. Efetividade dos direitos sociais: reserva do possível, mínimo existencial e ativismo judicial. Disponível em: http://www.ambitojuridico.com.br/site/index.php?n_link=revista_artigos_leitura\&arti-go_id=7701. Acesso em: julho 2020.

${ }_{6}^{6}$ BRASIL, Supremo Tribunal Federal. Agravo Regimental no Recurso Extraordinário com Agravo no 639.337 SP. Ministro Celso de Mello, Brasilia: DJe, 15 set 2011 . Disponível: http://redir.stf.jus.br/paginadorpub/paginador.jsp?docTP=AC\&docID=627428. Acesso: agosto de 2020
} 
Arguição de descumprimento de preceito fundamental. A questão da legitimidade constitucional do controle e da intervenção do Poder Judiciário em tema de implementação de politicas públicas, quando configurada hipótese de abusividade governamental. Dimensão politica da jurisdição constitucional atribuída ao Supremo Tribunal Federal. Inoponibilidade do arbítrio estatal à efetivação dos direitos socais, econômicos e culturais. Caráter relativo da liberdade de conformação do legislador. Considerações em torno da cláusula da "reserva do possível". Necessidade de preservação, em favor dos indivíduos, da integridade e da intangibilidade da arguição de descumprimento no processo de concretização das liberdades positivas (Direitos constitucionais de segunda geração.) ${ }^{7}$

Ou seja, trata-se de direitos que estão relacionados a necessidade básica para que a pessoa viva de forma digna, portanto, o firme fundamento de que a violação do mínimo existencial significa violação da dignidade da pessoa humana é uma premissa verdadeira.

Nesse plano, é possível observar o mais elevado padrão de afirmação da dignidade do ser humano nas relações trabalhistas, onde mesmo se tratando de uma relação privada não deixa de guardar, em si, o poder social com relevância jurídica, econômica e pública.

Essa premissa é perceptível no próprio contrato de trabalho. Este precisa atuar cercado de direitos fundamentais, como respeito a jornada de trabalho, salário mínimo, um ambiente de trabalho respeitável entre outros. Além disso, evita-se que o indivíduo que está cedendo sua força de trabalho seja tratado como uma mercadoria ou uma coisa, mas como um cidadão, sujeito de direito.

Portanto, emprego e renda não são relações exclusivamente privada, uma vez que cabe ao Estado garantir, por meio de prestações positivas, a parcela mínima para que cada um viva de forma digna e que atenda às necessidades classe trabalhadora.

Para Muniz (2010, p.203) “a política do salário mínimo tem por objetivo promover a justiça social e econômica, assegurando, legalmente, padrões de rendimento e consumo minimamente satisfatórios aos trabalhadores e suas famílias".

\footnotetext{
7 ADPF 45. Disponível: http://www.stf.jus.br/arquivo/informativo/documento/informativo345.htm. Acesso: agosto, 2020.
} 
Não obstante, ele continua e afirma que "um salário mínimo condizente com a definição constitucional é a premissa para se promover a cidadania, bem como para contribuir, de forma efetiva, com o desenvolvimento regional e social". 8

Destaca-se, assim, a importância de políticas públicas que entendam a interrelação social de direitos fundamentais e apliquem, visando o equilíbrio capital, trabalho e economia, com intuito de assegurar o mínimo para a dignidade da pessoa humana.

Para a doutrina dominante, uma política avançada é uma política que é visionária no cunho social, político e econômico. Conclui-se, portanto, que a garantia de emprego e renda, de forma digna, abrangendo direitos fundamentais individuais e sociais estimularia o desenvolvimento econômico, de acordo com a realidade social vigente, assegurando estabilidade social e econômica. Contudo, em tempo de crise, esses horizontes são ampliados e o Estado passa a agir da forma triádico duplo, conforme supramencionado, buscando um equilíbrio na crise e resguardar os direitos constitucionais, como é o caso do Programa Emergencial de Manutenção de Emprego e Renda que será analisado.

\section{POLÍTICA EMERGENCIAL DE MANUTENÇÃO DE EMPREGO E RENDA}

De fato, o impacto da epidemia do coronavírus sobre atividades econômicas requereu do governo medidas emergenciais em vários setores governamentais, porém destac-se a Medida Provisória ${ }^{\circ} 936$ que foi transformada em Lei n ${ }^{\circ}$ 14.020/2020 e instituiu o Programa Emergencial de Manutenção do Emprego e Renda, com intuito de diminuir os efeitos econômicos e sociais do Covid-19 e salvaguardando os direitos sociais mínimos a dignidade humana.

De acordo com o artigo $2^{\circ}$ da Lei 14.020/2020 o objetivo do programa é preservar o emprego, a renda dos trabalhadores e garantir a continuidade das atividades laborais e empresariais, bem como reduzir o impacto social decorrente das consequências do estado de calamidade pública e de emergência de saúde pública.

Primeiramente é possível observar a suspensão temporária do contrato de trabalho e a redução proporcional de salários e da jornada dos trabalhadores, mediante acordo individual ou negociação coletiva, até 90 dias. A lei dispõe a redução de $25 \%, 50 \%$ ou $70 \%$ do salário do

\footnotetext{
${ }^{8}$ Idem, p. 204.
} 
empregado e o governo complementa com o Benefício Emergencial de Preservação do Emprego e Renda.

Já no caso da suspensão temporária do contrato de trabalho dependerá do faturamento da empresa.

É possível visualizar benefícios sociais consequente da adoção da redução da jornada e salário através do seguinte exemplo:

Por exemplo, no caso de redução da jornada e salário de $25 \%$, se o empregado tiver sua base de salário em $\mathrm{R} \$ 1.580,00$, o empregador custeará $75 \%$ do salário, $\mathrm{R} \$ 1.185,00$, enquanto que o benefício custeado pela União, não será $25 \%$ de $\mathrm{R} \$ 1.580,00$ ( $\mathrm{R} \$ 395,00)$, na verdade será $25 \%$ de $\mathrm{R} \$$ $1.580,00 \times 0,80$, ou seja, $\mathrm{R} \$ 316,00$. Utilizando a mesma base de salário para o caso de suspensão do contrato de trabalho, a prestação mensal será R $\$$ $1.580,00 \times 0,80$, ou seja, $\mathrm{R} \$ 1.264,00$. O resultado do cálculo será arredondado para cima $\left(\$ 4^{\circ}\right.$ do art. $6^{\circ}$ da Lei $\left.n^{\circ} 14020 / 2020\right) .{ }^{9}$ (ALVES, 2020).

Contudo, apesar de aparentemente ser uma medida cabível a economia brasileira, a mesma vem recebendo diversas críticas. A começar pela sua abrangência limitada, uma vez que apenas trabalhadores diretamente afetados pela redução da jornada ou pela suspensão do contrato de trabalho podem participar do programa, os demais podem ser dispensados.

Além disso, a nota técnica do DIEESE no 232 acrescenta:

Não pode participar do programa o trabalhador que eventualmente receba benefício de prestação continuada do Regime Geral de Previdência Social ou dos Regimes Próprios de Previdência Social, ou que esteja em gozo do seguro-desemprego ou da bolsa-qualificação. Entretanto, pensionistas e quem recebe auxílio-acidente estão habilitados a participar. A MP também exclui trabalhadores que detenham cargos públicos, não se aplicando a empregados da administração pública direta ou indireta, de empresas estatais de sociedade de economia mista e suas subsidiárias. ${ }^{10}$

Embora as críticas existam, não se pode ignorar o fato de que o covid-19 desencadeou crise mundial, e que o governo brasileiro buscou, através dessa medida

\footnotetext{
${ }^{9}$ ALVES, Rogério. Suspensão e redução da jornada de trabalho. Entenda e legislação (covid-19). Publicado em 07/2020. Disponível: https://jus.com.br/artigos/83985/suspensao-e-reducao-da-jornada-de-trabalho-entendaa-legislacao-covid-19. Acesso: agosto de 2020. 10 https://www.dieese.org.br/notatecnica/2020/notaTec232ProgramaEmergencialGoverno.pdf. Acesso: agosto de 2020.
} 
emergencial auxiliar na preservação de empregos e de empresas, afim de que, posteriormente o período estabelecido pela lei, o cidadão tenha seu direito ao trabalho assegurado pelo programa governamental.

Porém, faz-se necessário divulgar o balanço do que já ocorrera com a MP 936 que atualmente foi sancionada a lei 14.020/2020.

De acordo com o Ministério da Economia, desde a publicação da MP que institui o benefício até o dia 26 de junho, 11,6 milhões de acordos individuais e coletivos foram celebrados e $\mathrm{R} \$ 17,4$ bilhões já estão na conta dos trabalhadores.

As reduções de jornada somam 6,1 milhões, as suspensões totalizam 5,4 milhões e os intermitentes 167 mil. Entre as reduções, 2,2 milhões são de $70 \%$. As reduções de $50 \%$ somam 2,1 milhões e as de $25 \%, 1,7$ milhão. ${ }^{11}$

Conclui-se que apesar de ser um grande desafio manter ativos postos de trabalho, esta política pública tem garantido o emprego de mais de 11 milhões de cidadãos, além disso, não tem medido esforços para injetar incentivos financeiros na economia buscando assim uma multidisciplinariedade no programa emergencial de emprego e renda.

\section{A REALIDADE DA POLÍTICA PÚBLICA EMERGENCIAL}

O cenário global trabalhista é preocupante e o direito do trabalho tem a função de se posicionar juntamente com a economia a fim de buscar alternativas dentro do campo trabalhista para mitigação dos efeitos econômicos e sociais da pandemia.

É importante salientar que Organização Internacional do Trabalho (OIT) tem diretrizes globais para mitigação dos impactos trabalhista e econômicos e suas atividades intentam para a proteção do trabalhador dentro e fora do ambiente de trabalho, exploração ao estímulo da economia e por fim incentiva seus estados-membros e tomarem medidas para manutenção de postos de trabalho, de investimento e renda. Além disso, há também a proteção social, apoio para manutenção de emprego e concessão de auxílios financeiro.

Outro ponto é que a OIT recomenda como política ativa para proteção dos empregos e da renda, a adoção de mecanismos de retenção de empregos, citando explicitamente a redução da jornada e as licenças remuneradas. Essa recomendação se insere em um conjunto

11 Agência Brasil. Lei que criou programa de manutenção do emprego é publicado. Disponivel: https://mercadonews.com.br/2020/07/07/lei-que-criou-programa-de-manutencao-do-emprego-e-publicada/. Acesso: agosto 2020. 
maior que abrange a proteção dos trabalhadores nos locais de trabalho, bem como o estímulo econômico e sustentação da demanda.

O Programa Emergencial de Emprego e Renda não só corresponde esse tripé e a esse mecanismo como também incentiva, economicamente, a manutenção de postos de trabalho. $\mathrm{O}$ alcance e os efeitos ainda não podem ser mensurados e os dados abaixo é apenas uma apresentação de modo a incentivar a reflexão em política pública emergencial.

$\mathrm{Na}$ primeira tabela ${ }^{12}$ o indicador é em relação ao rendimento mensal do emprego apenas a aplicação da redução da jornada e salário.

\begin{tabular}{|c|c|c|c|c|c|c|}
\hline \multirow{3}{*}{$\begin{array}{l}\text { SALÁRIO } \\
\text { NOMINAL } \\
\text { BRUTO }\end{array}$} & \multicolumn{6}{|c|}{$\begin{array}{l}\text { TABELA } 1 \\
\text { Cálculo da taxa de reposição do benefício emergencial } \\
\text { para redução de jornada e salário - em reais }\end{array}$} \\
\hline & \multicolumn{3}{|c|}{$\begin{array}{c}\text { SALÁRIO REDUZIDO + } \\
\text { BENEFICIO }\end{array}$} & \multicolumn{3}{|c|}{ TAXA DE REPOSIÇÃO } \\
\hline & $25 \%$ & $\mathbf{5 0} \%$ & $70 \%$ & $25 \%$ & $50 \%$ & $70 \%$ \\
\hline $1.045,00$ & $1.045,00$ & $1.045,00$ & $1.045,00$ & $100 \%$ & $100 \%$ & $100 \%$ \\
\hline $1.500,00$ & $1.425,00$ & $1.350,00$ & $1.290,00$ & $95 \%$ & $90 \%$ & $86 \%$ \\
\hline $2.000,00$ & $1.869,97$ & $1.739,94$ & $1.635,92$ & $93 \%$ & $87 \%$ & $82 \%$ \\
\hline $2.500,00$ & $2.307,47$ & $2.114,94$ & $1.960,92$ & $92 \%$ & $85 \%$ & $78 \%$ \\
\hline $3.000,00$ & $2.703,26$ & $2.406,52$ & $2.169,12$ & $90 \%$ & $80 \%$ & $72 \%$ \\
\hline $4.000,00$ & $3.453,26$ & $2.906,52$ & $2.469,12$ & $86 \%$ & $73 \%$ & $62 \%$ \\
\hline $5.000,00$ & $4.203,26$ & $3.406,52$ & $2.769,12$ & $84 \%$ & $68 \%$ & $55 \%$ \\
\hline $7.500,00$ & $6.078,26$ & $4.656,52$ & $3.519,12$ & $81 \%$ & $62 \%$ & $47 \%$ \\
\hline $10.000,00$ & $7.953,26$ & $5.906,52$ & $4.269,12$ & $80 \%$ & $59 \%$ & $43 \%$ \\
\hline $12.000,00$ & $9.453,26$ & $6.906,52$ & $4.869,12$ & $79 \%$ & $58 \%$ & $41 \%$ \\
\hline
\end{tabular}

Elaboração: DIEESE

Visualiza-se na tabela que apenas quem ganha um salário mínimo é que tem o benefício de forma integral, os demais têm perda.

Para os trabalhadores que terão seus contratos suspensos a tabela $2^{13}$ também mostra uma perda para quem ganha de $\mathrm{R} \$ 1.500,00$ para cima, vejamos:

12 DIEESE. Alcance do Programa Emergencial de Manutenção de Emprego e Renda. Disponível: https://www.dieese.org.br/notatecnica/2020/notaTec232ProgramaEmergencialGoverno.pdf. Acesso em: agosto 2020.

${ }^{13}$ Idem 


\begin{tabular}{|c|c|c|c|c|}
\hline \multirow{2}{*}{\begin{tabular}{c|} 
SALÁRIO \\
NOMINAL
\end{tabular}} & \multicolumn{2}{|c|}{$\begin{array}{c}\begin{array}{c}\text { FATURAMENTO }<\text { R\$ } 4,8 \\
\text { MILHÖES }\end{array} \\
\end{array}$} & \multicolumn{2}{|c|}{$\begin{array}{c}\text { FATURAMENTO > R\$ } \\
\text { 4,8 MILHŌES }\end{array}$} \\
\hline & BENEFICIO & \begin{tabular}{|c|} 
TAXA \\
REPOSIÇÃOO
\end{tabular} & $\begin{array}{c}\text { BENEF + } \\
\text { AJUDA }\end{array}$ & \begin{tabular}{|c|} 
TAXA \\
REPOSIÇÃOO \\
\end{tabular} \\
\hline $1.045,00$ & $1.045,00$ & $100 \%$ & $1.045,00$ & $100 \%$ \\
\hline $1.500,00$ & $1.200,00$ & $80 \%$ & $1.290,00$ & $86 \%$ \\
\hline $2.000,00$ & $1.479,88$ & $74 \%$ & $1.635,92$ & $82 \%$ \\
\hline $2.500,00$ & $1.729,88$ & $69 \%$ & $1.960,92$ & $78 \%$ \\
\hline $3.000,00$ & $1.813,03$ & $60 \%$ & $2.169,12$ & $72 \%$ \\
\hline $4.000,00$ & $1.813,03$ & $45 \%$ & $2.469,12$ & $62 \%$ \\
\hline $5.000,00$ & $1.813,03$ & $36 \%$ & $2.769,12$ & $55 \%$ \\
\hline $7.500,00$ & $1.813,03$ & $24 \%$ & $3.519,12$ & $47 \%$ \\
\hline $10.000,00$ & $1.813,03$ & $18 \%$ & $4.269,12$ & $43 \%$ \\
\hline $12.000,00$ & $1.813,03$ & $15 \%$ & $4.869,12$ & $41 \%$ \\
\hline
\end{tabular}

Elaboraçāo: DIEESE

É importante frisar, que embora os dados sejam relativamente motivador, os desafios se encontram em promover essa politicas aos trabalhadores informais, bem como àqueles dispensados antes da Medida Provisória e que possivelmente estejam recebendo as últimas parcelas do seguro-desemprego e não menos importante, a melhor atuação das centrais sindicais, visto que a mesma tem maior habilidade de propor medidas de aplicação e implementação a favor dos trabalhadores.

No entanto, não pode ignorar o fato que a influência desta política pública incentivou diversas empresas e garantiu muitos postos de trabalho. $\mathrm{O}$ foco a partir de agora é olhar para o futuro guardando as experiencias do presente e assim, vislumbrar novas alternativa multidisciplinares e efetivas para melhor elaboração e implantação de políticas públicas.

\section{NUDGE: UMA ALTERNATIVA?}

Vislumbra-se em um atual cenário uma tendência transdisciplinar entre as ciências que possibilitam uma melhor compreensão da realidade social e a elaboração de instrumentos políticos que incentivam resultados mais efetivos para a sociedade.

Partindo desse cenário de oportunidades, de primeira precisa ser entendido alguns conceito, como a análise econômica tradicional que conclui que as pessoas racionais reagem a estímulos a que estão sujeitas, pois suas tomadas de decisões são de acordo com os custos e benefícios, ou seja, as mesmas analisam zelosamente as vantagens e desvantagens quando precisam tomar uma decisão.

Em contrapartida, a análise comportamental acredita que os seres humanos não são tão racionais quanto parecem, uma vez que suas decisões são baseadas em mecanismos 
emocionais e cognitivos, limitados e inconsciente, com padrões emocionais não saudáveis e que podem fazer escolhas contrarias aos seus próprios interesses ou até mesmo contra seu bem-estar.

Nessa perspectiva o ser humano é observado como um ser que decide com base em hábitos, experiencias pessoas, bem como não tem facilidade de separar e até mesmo conciliar interesses curtos e longo prazo e quando são bombardeados de informações, automaticamente, criam atalhos, ou seja, escolhem o mais fácil para então tomar decisões de forma mais rápida e, por isso, são fortemente influenciados por fatores emocionais e afetivos por aqueles que o rodeiam.

Diante disso, verifica-se a abertura de oportunidade onde a elaboração de políticas públicas podem ser direcionadas pelo fundamento da economia comportamental. Através dessa ciência, entende-se que o governo irá dá um 'empurrãozinho', nudges, para que a pessoa tome uma decisão correta, de acordo com o interesse público.

O termo "arquitetura das escolhas" estudado pelo nobel Richard h. Thaler e Cass R. Sunstein aborda a economia tradicional com a psicologia comportamental concluindo que o indivíduo toma decisão sob aspectos conscientes e inconsciente e por diversas influencias.

Para entender melhor os pesquisadores Amanda, Déhbora e Saul (2018, p. 273) arguiram:

\footnotetext{
A arquitetura das escolhas ou nudge é uma teoria que pode ser conceituada como uma intervenção no desenho de organização de possibilidades de escolha de uma pessoa, que estimula um determinado comportamento, sem, contudo, restringir a liberdade de decisão desta.

[...]

Nudge é uma palavra da Língua Inglesa que, segundo o Cambridge dictionary, significa empurrar ou cutucar. Sustein define nudge como uma intervenção que preserva a liberdade de escolha, ainda que possa influenciar a tomada de decisão.
}

Portanto, o nudge não busca coagir, mas induzir, influenciar e estimular a tomada de decisão. Embora seja alvo de diversas críticas, uma delas é sobre a liberdade de escolha, porém acredita-se que as pessoas não são totalmente livres, estão sob diversos fatores do dia a dia, muitas vezes em alto grau de complexidade e que, consequentemente, influenciam diretamente nas escolhas. O ser humano acaba utilizando de forma automática e isso interfere, indubitavelmente, na qualidade de suas escolhas. 
Partindo-se dessas considerações, Thaler e Sunsteim desenvolvem a Teoria da Arquitetura das Escolhas ou nudging, que defende que é possível a organização do contexto no qual as pessoas tomam decisões, com objetivo de influenciá-las de forma previsível pela ciência.

A partir desse viés e com o estudo heurístico e análise das escolhas do passado juntamente elaborando de forma inteligente a arquitetura da escolha é possível ajudar cada pessoa a tomar decisões assertivas.

É importante destacar, que embora pareça retirar a liberdade individual, o nudge preserva o poder de decisão de cada um. No que se refere ao serviço público é necessário cautela, pois esse 'empurrãozinho' precisa obedecer ao princípio constitucional da transparência e moralidade.

Partindo-se dessas considerações e das contribuições da análise econômica comportamental do direito, mormente no que concerne ao estudo dos fatores que influenciam as escolhas e as decisões das pessoas, verificar-se-á como os nudges podem ser elaborados sob o prisma governamental.

Então como conciliar os nudges com as ações positivas do Estado? Seria através de estímulos de comportamentos por meio de leis, políticas públicas e medidas governamentais?

No que concerne a política pública, compreende-se como uma ação multifacetadas, com objetivo e prazos estabelecidos e que se desenvolve no seguinte ciclo $^{14}$ :

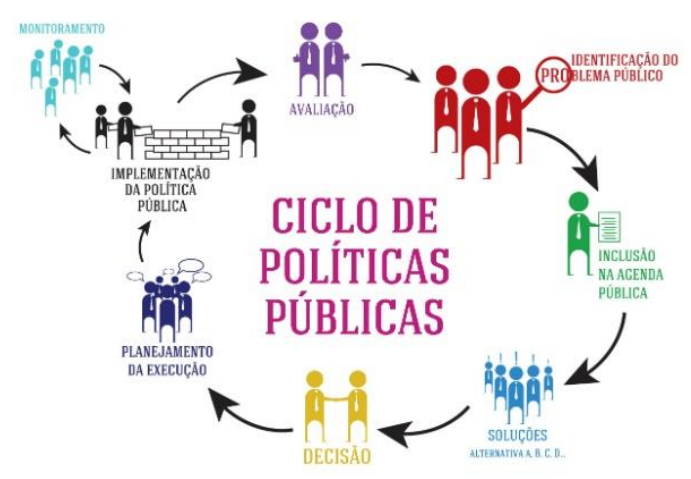

Observando esse ciclo, o nudge influencia na fase de soluções, onde formulará e estimulará na tomada de decisão. Utilizando-se de uma dessas formas de empurrão na

\footnotetext{
${ }^{14}$ https://politicaspublicas.almg.gov.br/sobre/index.html. Acesso em: agosto de 2020.
} 
arquitetura das escolhas sociais, o Estado pode elaborar vários nudges, que conduzem, previnam ou desestimulem determinados comportamentos.

Diante de toda a apresentação teórica pretende-se identificar os nudges como instrumento eficaz de implantação e ação de políticas públicas, principalmente em relação à proteção do trabalhador. O mercado globalizado, tecnológico, crises sociais, financeira entre outros são os desafios enfrentados pelo Estado brasileiro na efetivação de políticas públicas na esfera trabalhista.

Para enfrentar a atual crise o governo apresentou o Programa Emergencial de Emprego e Renda que tem como objetivo beneficiar milhares de trabalhadores com a manutenção de seu posto de trabalho, dessa forma, vislumbra-se um melhor estudo sobre como o nudge poderia evitar diversas polêmicas e críticas, utilizando o caos social poderia obter resultados muito mais eficientes e mais baratos.

O relatório MINDSPACE Behavioural Economics, divulgado pela Cabinet office e o Institute for Government ${ }^{15}$ da Inglaterra, propõe nove aspectos que podem interferir quando se fala em influenciar o comportamento das pessoas via política pública.

Vale lembrar que a pretensão deste artigo não é exaurir o assunto, aqui é o início de uma reflexão e em como esse mecanismo pode influenciar um Governo e o Brasil com políticas públicas mais bem selecionadas e implementadas. Dessa maneira, ressaltaremos apenas os três primeiros aspectos.

A começar pelo mensageiro. A premissa é que quem passa a informação e o modo como ela é passada tem implicação na força com que a mensagem é assimilada. Um exemplo simples com a Lei 14.020/20 é: quem deveria comunicar as medidas era um líder do meio social do grupo do empregado em conjunto com um líder do grupo de empregadores. Segundo a ideia do nudge a informação iria ser envolvida de força e influencia.

O segundo ponto é o incentivo, com ele há uma grande influência em mudanças de comportamentos. Nesse ponto, é preciso ressaltar que as pessoas preferem evitar perdas a ter

\footnotetext{
15 Institute for Government. Mindspace Behavioural Economics. Disponível em: https://www.instituteforgovernment.org.uk/our-work/better-policy-making/mindspace-behavioural-economics. Acesso em: agosto de 2020.
} 
ganhos de valor equivalente, assim as políticas públicas devem focar não nos prêmios, mas nas perdas que acontecerão se determinado comportamento não for adotado.

E o terceiro, não menos importante, se refere às normas sociais. As pessoas tendem a repetir o que os outros fazem, então a ideia da medida de manutenção de emprego e renda era o governo focar o quanto as empresas estão aderindo a Lei $\mathrm{n}^{\circ} 14.020 / 20 \mathrm{e}$ o quanto os trabalhadores estão sendo beneficiados pelo programa emergencial.

Com isso, é importante frisar que o nudge precisa passar por um estudo e uma estrutura que se encaixe com o modelo governamental brasileiro, no entanto, não se pode ignorar os benefícios do modelo comportamental em diversos setores de políticas públicas, principalmente na área da saúde, educação e para proteger a dignidade do cidadão, como o direito ao trabalho.

\section{CONSIDERAÇÕES FINAIS}

Claramente, as pessoas são levadas por um senso de justiça e direito conforme suas emoções, e, portanto, alguns estudos demonstraram que as pessoas não possuem capacidade cognitiva para decidir tudo de maneira adequada. Nesse cenário, os gestores públicos devem ser conscientizados de que podem utilizar outros mecanismos para formular políticas públicas capazes de auxiliar as pessoas no processo de escolha.

A possibilidade do uso de nudges para fortalecer políticas públicas direcionadas ao trabalho apresenta-se como uma alternativa de efetivação imediata e simples, de baixo custo e sem imposição ao usuário de políticas públicas efetivas e capazes de produzir mudança comportamental, proporcionando efeitos positivos individual e coletivamente.

Apesar de o nudges ser considerado uma técnica relativamente nova na esfera pública, os resultados são promissores, justificando sua utilização como instrumento de estruturação de políticas públicas ao trabalho e desenvolvimento social.

É nesse viés que pode iniciar uma reflexão, pois com esse novo mecanismo pode ser obtido maiores e melhores resultados utilizando pouquíssimos recursos. Embora seja rodeadas de críticas, as quais são necessárias para o aperfeiçoamento, esse mecanismo é real e pode ser adotado tanto em tempos de crises como para construir um novo caminho social-democrático. 
Por fim, analisando a política pública do programa emergencial de manutenção de emprego e renda entre outras medidas governamentais, impõe-se a interdisciplinaridade para proporcionar o avanço nacional em direção a melhores condições de vida. Não basta a Constituição Federal estabelecer o trabalho como direito fundamental, se não forem adotadas políticas públicas para garantir efetividade a tal direito.

\section{REFERENCIAS}

$\mathrm{ADPF}$

45.

Disponível: http://www.stf.jus.br/arquivo/informativo/documento/informativo345.htm. Acesso: agosto, 2020.

Agência Brasil. Lei que criou programa de manutenção do emprego é publicado. Disponível em: https://mercadonews.com.br/2020/07/07/lei-que-criou-programa-demanutencao-do-emprego-e-publicada/. Acesso em: agosto de 2020. 
ALVES, Rogério. Suspensão e redução da jornada de trabalho. Entenda e legislação (covid-19). Publicado em 07/2020. Disponível: https://jus.com.br/artigos/83985/suspensao-ereducao-da-jornada-de-trabalho-entenda-a-legislacao-covid-19. Acesso em: agosto 2020.

BARCELlOS, A. P. de. A eficácia jurídica dos princípios constitucionais. O princípio da dignidade da pessoa humana. Rio de Janeiro: Renovar, 2002. In: MORAES, D.P.H. Efetividade dos direitos sociais: reserva do possível, mínimo existencial e ativismo judicial. Disponível em: http://www.ambitojuridico.com.br/site/index.php?n_link=revista_artigos_leitura\&arti-go_id=7701. Acesso em: julho 2020.

BRASIL, Supremo Tribunal Federal. Agravo Regimental no Recurso Extraordinário com Agravo no 639.337-SP. Ministro Celso de Mello, Brasilia: DJe, 15 set 2011. Disponível:http://redir.stf.jus.br/paginadorpub/paginador.jsp?docTP=AC\&docID=627428.

Acesso: agosto de 2020.

COELHO, Rodrigo Batista. Direitos Fundamentais Sociais e Políticas Públicas. São Paulo: Habermann, 2017.

CUNHA, Bruno Santos. Direitos fundamentais da constituição às políticas públicas. Revista Brasileira de Políticas Públicas, Brasília, v. 1, n. 1, 2011.

DIEESE.

Disponível:

https://www.dieese.org.br/notatecnica/2020/notaTec232ProgramaEmergencialGoverno.pdf.

Acesso: agosto de 2020.

DIEESE. Primeiros impactos da pandemia no mercado de trabalho. Disponível: https://www.dieese.org.br/boletimempregoempauta/2020/boletimEmpregoEmPauta15.pdf.

Acesso em: agosto 2020.

Institute for Government. Mindspace Behavioural Economics. Disponível em: https://www.instituteforgovernment.org.uk/our-work/better-policy-making/mindspacebehavioural-economics. Acesso em: agosto de 2020.

LEIVAS, Paulo Gilberto Cogo. Teoria dos Direitos Fundamentais Sociais. Porto Alegre: Livraria do Advogado, 2006.

Ministério da Economia. Programa Emergencial de Manutenção de Emprego e Renda. Disponível em: https://servicos.mte.gov.br/bem/. Acesso: 20 de setembro de 2020.

MUNIZ, M. K. C. B. O direito fundamental ao salário mínimo digno: uma análise à luz do princípio da dignidade da pessoa humana. São Paulo: LTr, 2010.

SILVA, Amanda Carolina Souza; RODRIGUES, Déhbora Renata Nunes; TIBALDI, Saul Duarte. Nudges e políticas públicas: um mecanismo de combate ao trabalho em condição análogo à de escravo. Ver. Bras. Polit. Pública, Brasilia, v8, nº 2, 2018. 